\title{
The development of internet based ship design support system for small and medium sized shipyards
}

\author{
Sung-Chul Shin ${ }^{1}$, Soon-Sup Lee ${ }^{2}$, Dong-Hoon Kang ${ }^{2}$ and Kyung-Ho Lee ${ }^{3}$ \\ ${ }^{1}$ Pusan National University, Department of Naval Architecture \& Ocean Engineering, Pusan, Korea \\ ${ }^{2}$ Gyeongsang National University, Department of Naval Architecture \& Ocean Engineering and \\ Institute of Marine Industry, Tongyeong, Korea \\ ${ }^{3}$ Inha University, Department of Naval Architecture \& Ocean Engineering, Incheon, Korea
}

\begin{abstract}
In this paper, a prototype of ship basic planning system is implemented for the small and medium sized shipyards based on the internet technology and concurrent engineering concept. The system is designed from the user requirements. Consequently, standardized development environment and tools are selected. These tools are used for the system development to define and evaluate core application technologies. The system will contribute to increasing competitiveness of small and medium sized shipyards in the 21st century industrial en-vironment.
\end{abstract}

KEY WORDS: Ship basic planning system; Small and medium sized shipyard; ActiveX; ASP; COM; Internet based design.

\section{INTRODUCTION}

Concurrent Engineering is a way of work where the various engineering activities in the production development process are integrated and performed as much as possible in parallel rather than in sequence. Concept of concurrent engineering is that the designer considers all product life-cycle aspects from earliest design stages, through manufacturing, deployment, operation, and even disposal (Pedro, 1997).

Internet began from integrating small area network such as LAN based on TCP/IP protocol and it grew to be a vast network covering the whole world. The main advantage of using internet is that it can support graphic user interface (GUI) through web browsers, completely different from previous text based environment.

A number of core technologies are necessary in order to support various engineering systems and services (design support system, analysis system, etc) with the internet. Among those systems and services, ASP (Application Service Provider), AcitiveX and COM (Component Object Model) technology enable easier access to using internet for engineering systems (Schaffran and Dallas, 1997).

Until now, most of the efforts are spent on the automation and computerization either within a unit process such as CAD, CAM and CAE, or across these unit processes. However, in the current, more researches will be focusing on the computer aided collaborative work among distributed expert groups based on internet (Lee, et al., 2006).

Ship design process in small and medium sized shipyards and design agent offices includes contract related activities such as defining ship specifications, construction planning, cost estimation, power estimation, main engine selection, drawing, basic calculation, and requires close co-work among shipyards, ship owner and design agents. While the activities occur mainly at the design department inside the shipyard for the major shipyards, the activities occur at many places such as shipyards and design agents for the small and medium sized shipyards. Therefore, a new design paradigm for small and medium sized shipyards and

Corresponding author: Soon-Sup Lee

e-mail:gnusslee@gnu.ac.kr 
design agents are required for the above close co-work. Moreover, the technological level of small and medium sized shipyards is relatively lower than that of major shipyards. A necessity of such technology for the collaborative work is prominent from the small and medium sized shipyards.

In this paper, a prototype system for internet based collaborative design environment is developed for small and medium sized shipyards. First, a framework is designed from the user requirements. Then standardized development environment and tools are selected. These tools are used for defining and evaluating core application technologies for the system development. Then the prototype system is developed.

For concurrent engineering to be successful, cross-functional design teams, along with their associated data, must be brought together. The developed system assists in implementing a concept of concurrent engineering successfully, providing the mechanism to capture and enforce the ship design process consistently according to the way that the ship-yard want to do it.

\section{KEY TECHNOLOGIES FOR REMOTE DESIGN}

\section{STEP (STandard for the Exchange of Product)}

STEP is an international standard (ISO 10303) for the computer-interpretable representation and exchange of product model data. The objective is to provide a neutral mechanism capable of describing product data throughout the life cycle of a product, independent from any particular system. The application protocols (APs) formulate the requirements of the product data to be handled in the scope of a certain industrial area. These are documented in the Application Reference Model (ARM), which is part of each AP. To achieve this, the terminology of the industry is used. APs provide the basis for the implementtation of STEP as the APs describe what data is to be exchanged.

Ship STEP (Lee, et al., 2003; Hwang, 2010) should be central to each of the APs structure such that the information is structured and organised in a consistent and similar manner, and is known as the Ship Common Model (SCM). The Ship Common Model forms the basis for all shipbuilding AP ARMs under development and to come. It provides a modeling framework for the APs that represent the Ship Product Model, a set of independent and reusable product-structure Domain Models that are required for more than one Application Protocol. As well as a set of commonly used constructs referred to as Common Utilities such as those used for configuration control and management concepts. The goal of the Ship Common Model is to ensure to the integration and overall consistency of the ARMs of the different ship APs. Thus, it is a means of integrating the requirements specified to a uniform conceptual model.

The full series of possible ship application protocols (AP) is shown in Fig. 1.

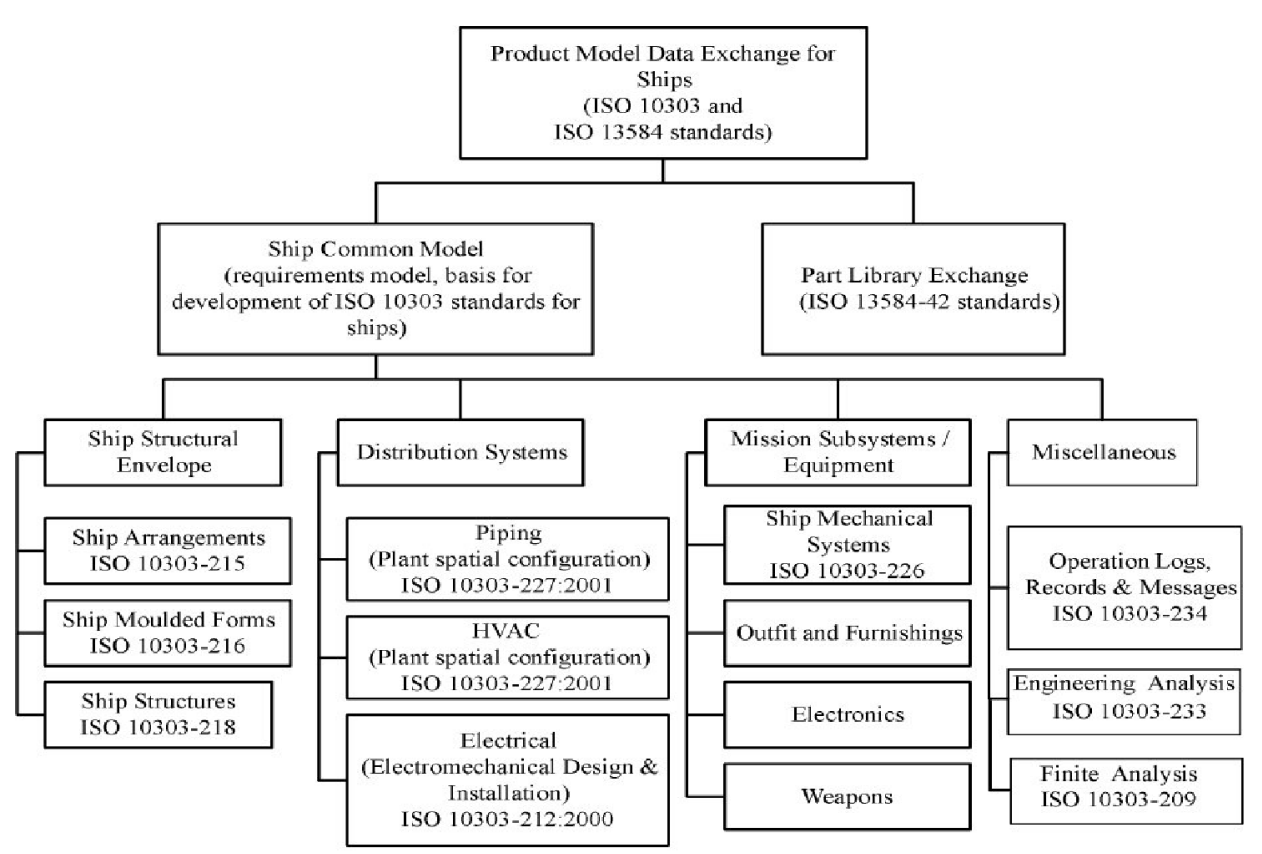

Fig. 1 An application protocol of ship STEP. 


\section{ActiveX}

The exchange and sharing of information through World Wide Web (WWW), together with the distribution of powerful personal computers that can be used as desktops or servers, and rapidly increase the work efficiency of each individuals and the whole enterprise.

ActiveX(Chun, 1997) is an open platform which enables rapid and easy development of internet/intranet integrated applications and contents by integrating the benefits of WWW and personal computers. In other words, ActiveX pro-vides users and developers with a platform that provides innovative functions on internet/intranet while reusing previous knowledge, application and code. ActiveX is a set of technologies that use component object model (COM) so that each software components can interact with each other without regards to the language which they are implemented with. It can be used to build applications running on desktops or internet.

ActiveX technology integrates PC platform and internet, and implements general application software on internet including animation, 3D virtual reality and movie using component software, script language and application.

\section{COM (Component Object Model)}

COM is a specification defining the standard communication method between the components and clients(Lee, et al., 2000). OLE (Object Linking and Embedding) and ActiveX are based on COM. COM components are generally composed in EXE or DLL (Dynamic Link Library) file type server applications, and more than one COM component can be implemented in a server application. The application providing service using COM components is called server, and the application using this service is called client. All COM components supports more than one type of interface and each interface are composed of more than one method. A method is a function or a procedure performing a certain kind of action, and can be called by client application using COM component. An interface is a contract between a COM component and the client using the component. Therefore, if a client is using the interface of a COM component, the interface cannot be modified. There are two types of interface: In-Process type and Out of Process type. The component and client use ActiveX DLL or EXE files to perform interface.

\section{ASP (Application Service Provider)}

ASP is an online business application program service. The user enters data into internet and ASP acquires/transfers the data and visualizes its results (Song, 1998; Lee, 2000).

There are two methods to implement ASP: using Windows Terminal Service and using Java.

\section{THE DEVELOPMENT OF THE REMOTE DESIGN SUPPORT SYSTEM FOR SMALL AND MEDIUM SIZED SHIPYARDS}

Major shipyards in Korea have focused on changing labor intensive aspect of shipbuilding to knowledge intensive activities in order to maintain their competitiveness against fast growing China by the introducing information tech-nology (Lee and Lee, 2008). However, small and medium sized shipyards have relatively lower technological level. The information exchange between shipyards and design agents is not only small in size but also lack in quality since most information is exchanged by means of 2D drawing. The use of computer system in design activities are still in its primitive stage, and mostly rely on the experience of experts rather than reusing previous information.

The basic planning stage of ship design is important since it has large effects on the following processes and the accuracy of the design document at this stage will affect the total design time. Therefore, computerizing and integrating the repeated processes in concept design and basic planning stage will increase the ease of interactions and the overall design efficiency.

In this paper, a prototype system for internet based collaborative design environment is developed for small and medium sized shipyards. First, a unit program is developed from user requirements. The each unit program is integrated for design efficiency and user friendliness. In addition, the developed system is capable of performing design activities such as previous ship data search, weight estimation, power calculation and basic calculation remotely using internet.

\section{The design process in small and medium sized shipyards}

Most small and medium sized shipyards have difficulties in distributed design environment. Typically, basic planning and 
initial design are done in design agents outside the shipyards, and outfitting and detailed designs for construction are done in the shipyards.

The tasks, which were manually done for small and medium sized ships, are now being computerized using design support systems and CAD systems (Lee, Lee and Park, 2004). However, most of the data exchange between design agents and the shipyards in transferring phase from design to construction are still done using drawings. In major shipyards, many researches are focusing on the exchange of design data between design systems. Their aim is to develop a uniform design system and standardization of design information.

Fig. 2 shows the design process in distributed environment taking account of internet.

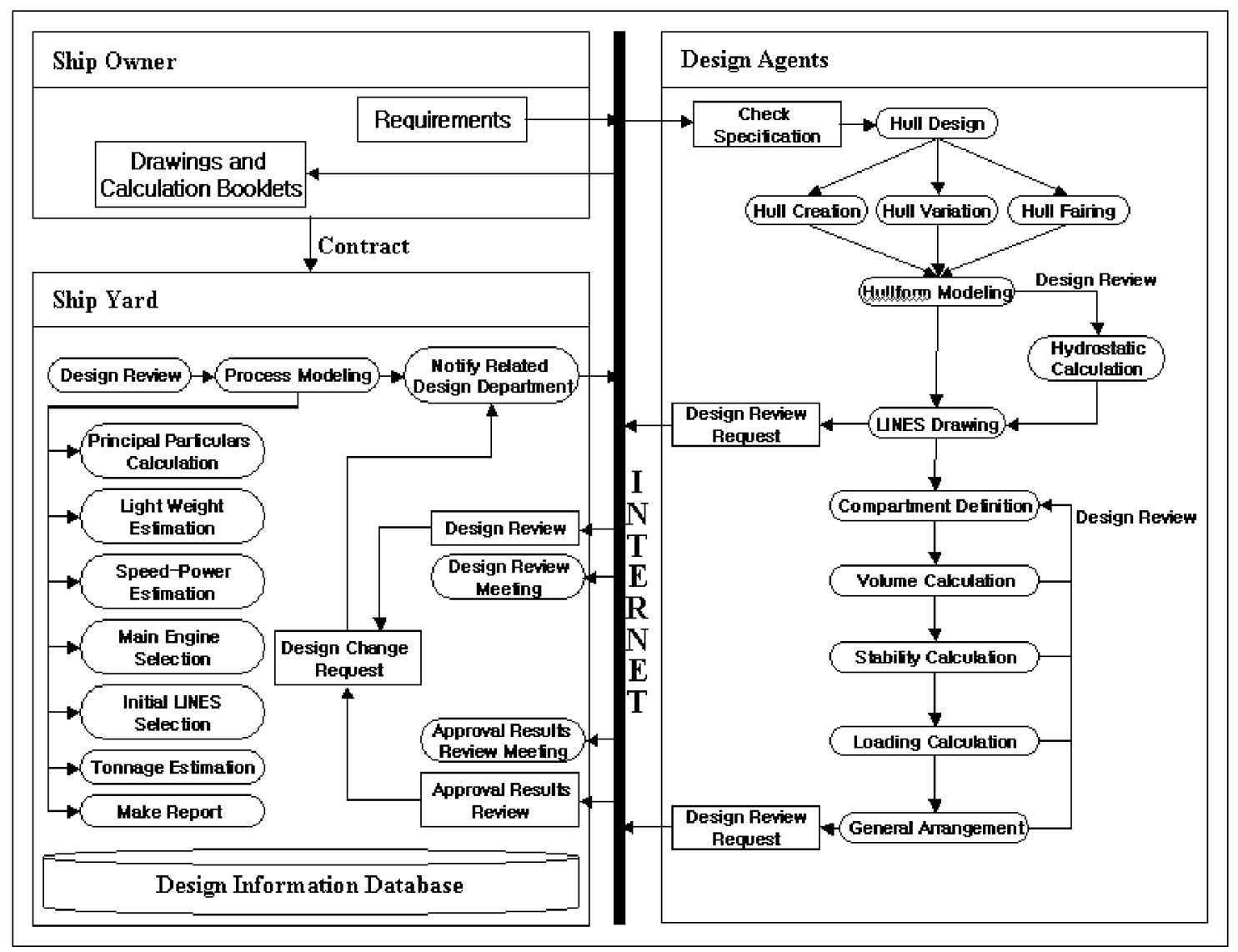

Fig. 2 An internet based design process for small and medium sized shipyards.

\section{The internet based basic planning support system}

In this paper, a support system for basic planning and calculation process of design agents and shipyards is implemented. The system uses user privilege control functions and PKI(Public Key Infrastructure) for security and user management. User privilege control provides functionalities which is necessary to control all user privileges for system usage and registering/ managing users. Also data access is managed by the privileges user group. PKI security system is used for user verification and data encryption. 1024 byte public key and 128 bit private key is used for user verification. In addition, since all security module functions are performed by Active-X Plug-In, the user does not have to install separate software.

\section{Development environment and tools}

Table 1 shows environment and tools used in developing the prototype system. Several design support programs (principal particulars selection, weight estimation, hull variation, longitudinal strength calculation and speed power calculation, etc) are implemented using Digital Fortran, and DLL(Dynamic-Link Library) is used as the interface between the support programs. In addition, the results are visualized using 3D graphic library, OpenGL. Windows 2000 Server/Professional PC is used for the 
design information exchange between design agents and shipyards, and the programs are executed on web browser. This system requires Microsoft Internet Explorer version 5.0 or higher.

Table 1 Development environment and tools.

\begin{tabular}{|l|l|}
\hline Type & Environment and tools \\
\hline Hardware & PC platform \\
\hline OS & Windows 2000, NT \\
\hline Language & ActiveX, Digital Fortran, Visual Basic \\
\hline Database & File DB \\
\hline GUI & ActiveX Document \\
\hline Graphic Library & OpenGL, GLUT \\
\hline Web Browser & Internet Explorer 7.0 or higher \\
\hline
\end{tabular}

\section{Development of the design support system}

The system is divided into user management module, basic planning support module, and basic calculations module. The user management module organized two different types of users; administrator and user. The basic planning support system module has functionalities such as requirement input, existing ship search, principal particulars estimation, power estimation and weight estimation. The basic calculations module has functionalities such as hull definition, hull variation, hydrostatic calculations, volume and volume center calculation, undamaged and damaged stability calculation, definition of compartments and longitudinal strength calculation.

The developed system will automatically read the data required from prior process for user convenience and consistency of data. Fig. 3 shows the system diagram.



Fig. 3 System diagram of developed system.

\section{Initial screen}

The developed system has the initial screen. The user logs on using user ID and password. The user having administrator privilege can create the ID and password. The ID and password are case sensitive. 
Fig. 4 shows the screen of menu, which represents the sub module of the developed system. The sub modules were developed based on user requirement.

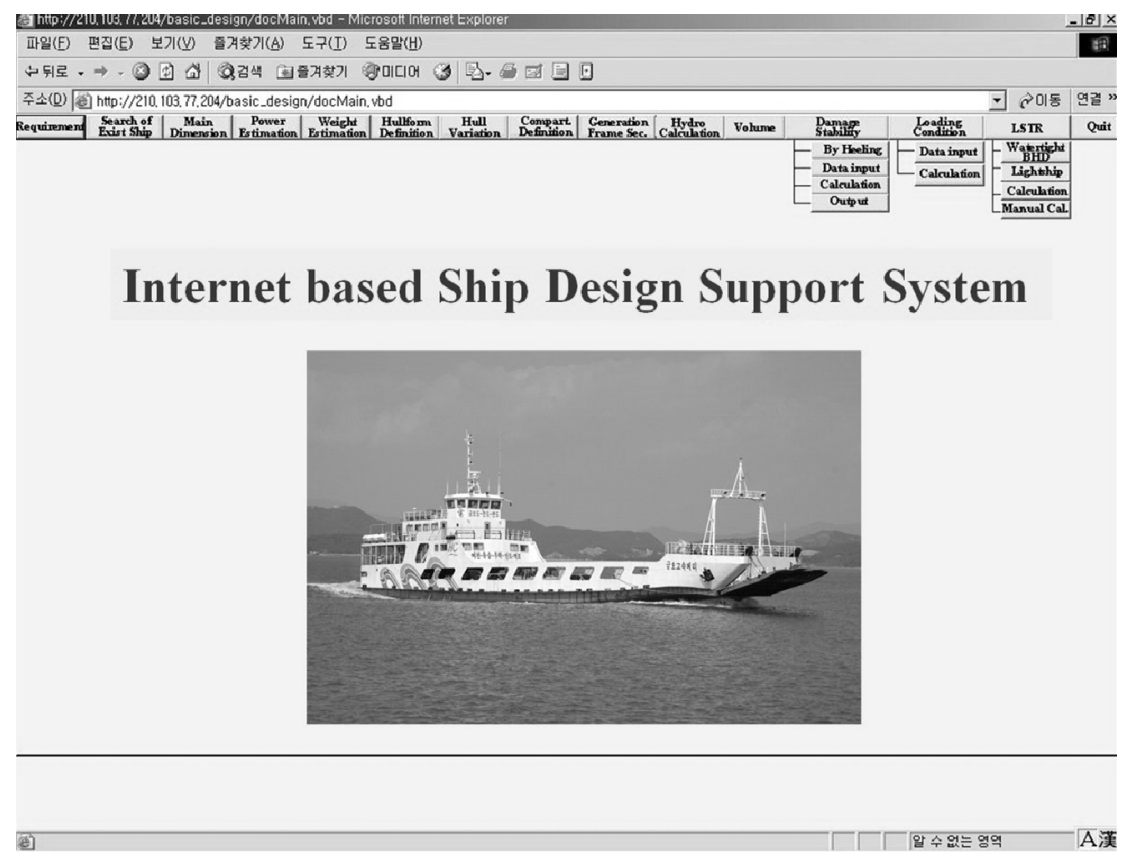

Fig. 4 Main menu of developed system.

\section{User management}

There are two types of users: administrator and user. The administrator manages the whole system and the user data. The management of user data includes ID, password, and other user related information. When creating a new user, ID and password data is compulsory and other data is optional. The user can log on to the system using user ID and password given by the administrator and perform various design tasks.

Fig. 5 shows the initial screen of the user management. It shows the user who can access the system.



Fig. 5 User management screen. 


\section{Basic planning support program}

The basic planning stage in shipyards is the stage before the contract with a ship owner. In the stage, basic per-formance, cost, construction period, equipments, etc are defined and are a basis data of the tasks performed in basic design, detailed design and construction stage. In addition, the tasks in basic planning stage should be done in cooperation with various institutes such as class society, equipment manufacturers and other departments in the shipyard. Therefore, internet based information system, the concept of concurrent engineering and collaborative design are required. The basic planning support module is designed to support the above tasks.

Fig. 6 shows the results of existing ship DB search where the existing ship data is sorted by total tonnage. The mother ship is selected by first clicking the mother ship number using mouse and press the button titled 'Mother Ship'.

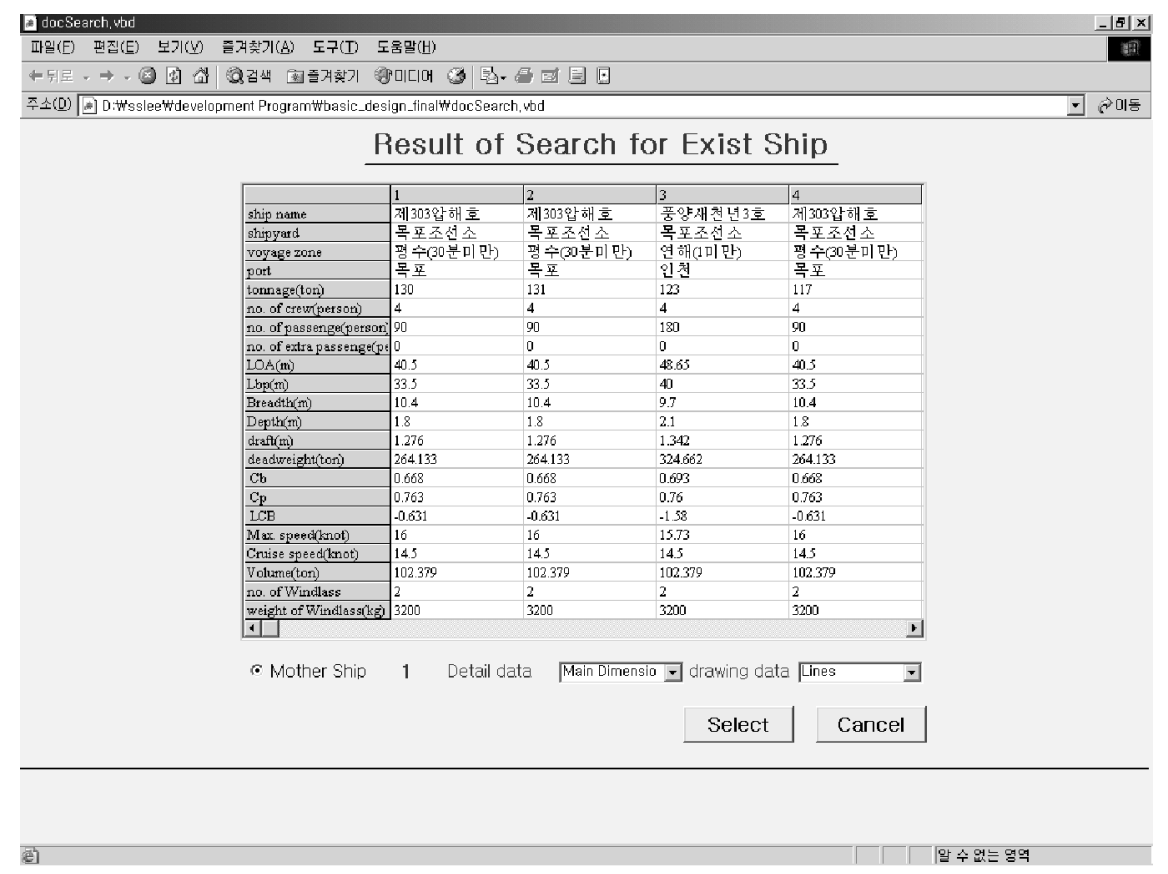

Fig. 6 Existing ship search results screen.

Fig. 7 shows the hull form of the mother ship. The hull form is the collection of geometry that defines the shape of the hull of the ship. For the hull form modeling, the basic curves (centerline contour, bottom tangent, side tangent, frame lines, waterlines, etc) are defined by using the offset data from ship DB.

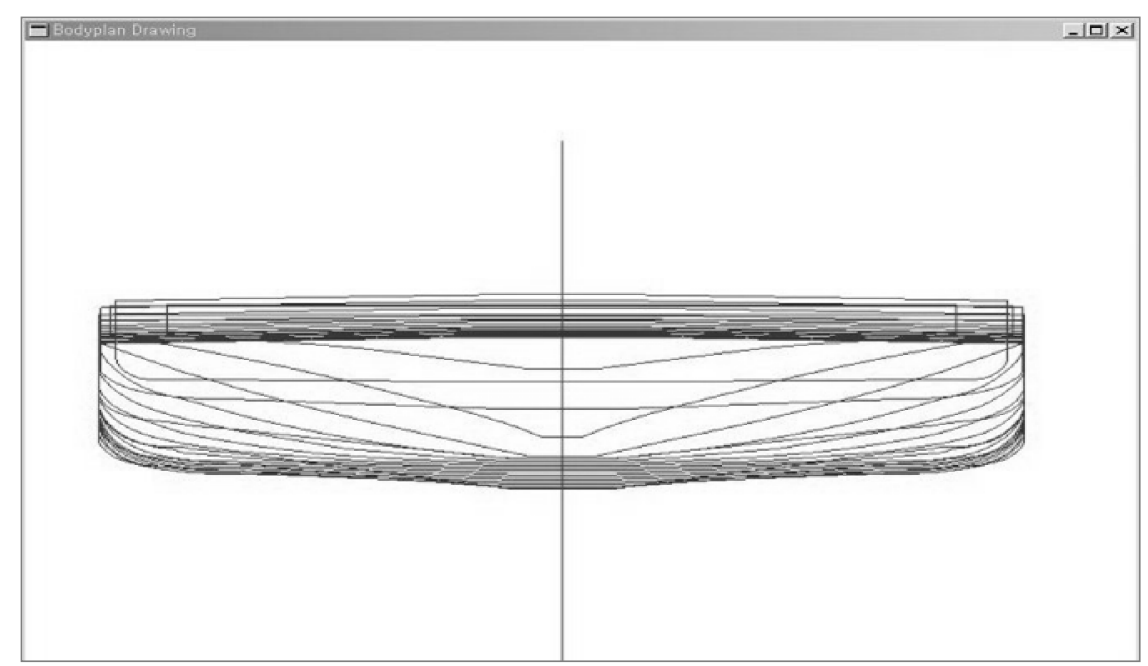

Fig. 7 Body plan of mother ship. 
Fig. 8 shows the principal particulars estimation process. The screen shows the principal particulars of the mother ship and estimated principal particulars of the ship being designed. As shown in the figure, there is difference of $1.539 \%$ in gross tonnage between the requirement and the ship being designed.

Fig. 9 shows input data screen for PNM72 (in-house program: the power estimation program), a resistance/ propulsion analysis program, used in power estimation. The mother ship data is automatically entered by the system based on the estimated principal particulars and existing ship data.

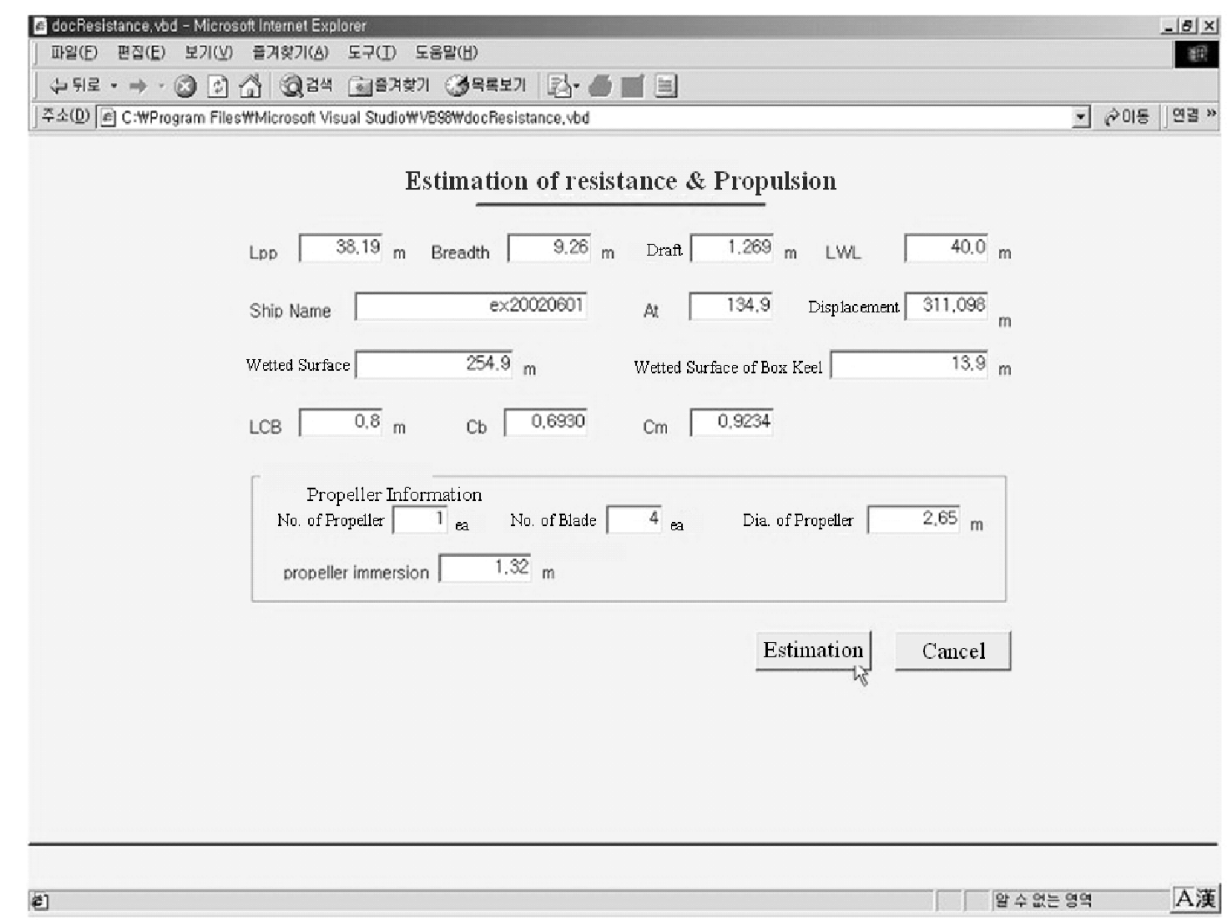

Fig. 8 Principal particular estimation screen.

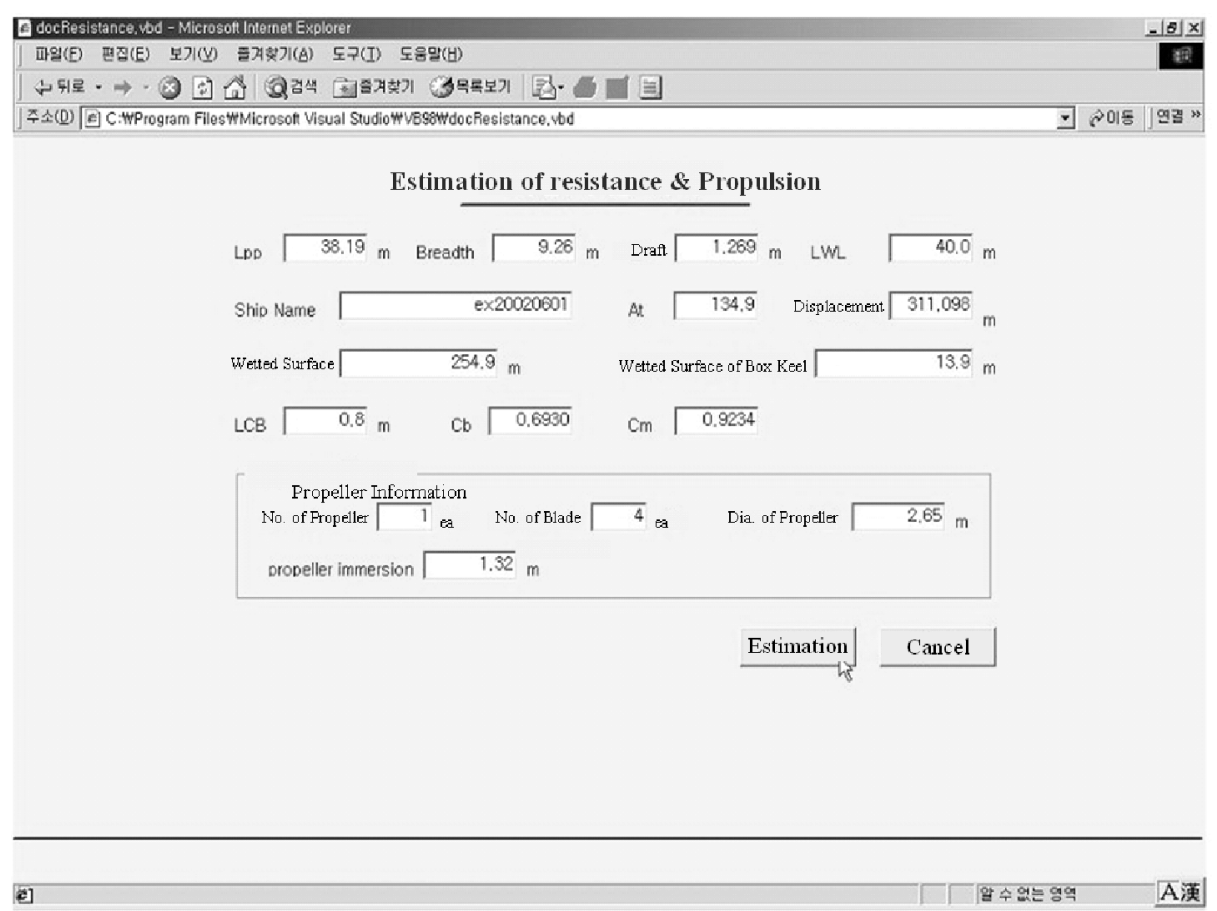

Fig. 9 Power/propulsion estimation screen. 


\section{Basic calculation program}

The basic calculation program performs hydrostatic calculations, volume calculations, stability calculations, loading condition calculation, longitudinal strength calculation, etc. The results are used as the basic data for stability evaluation of the ship being designed.

Fig. 10 shows output screen for the hydrostatic calculations and the input data. The results are visualized for each draft defined by the range and interval. For the draft that is not included in the range or interval, the result of hydrostatic calculations for a specific draft can be displayed with entering the draft in 'Special Draft' box. The results are shown as a table including displacement, CB, CP, LCB and LCF.

Fig. 11 shows the hydrostatics curve. The hydrostatics curve is visualized the results data of displacement, MTC, TPC, KMT, LCF, CB, CP, CW, CVP, and LCB for each draft.

Fig. 12 shows the input data screen for the stability calculation according to loading condition.

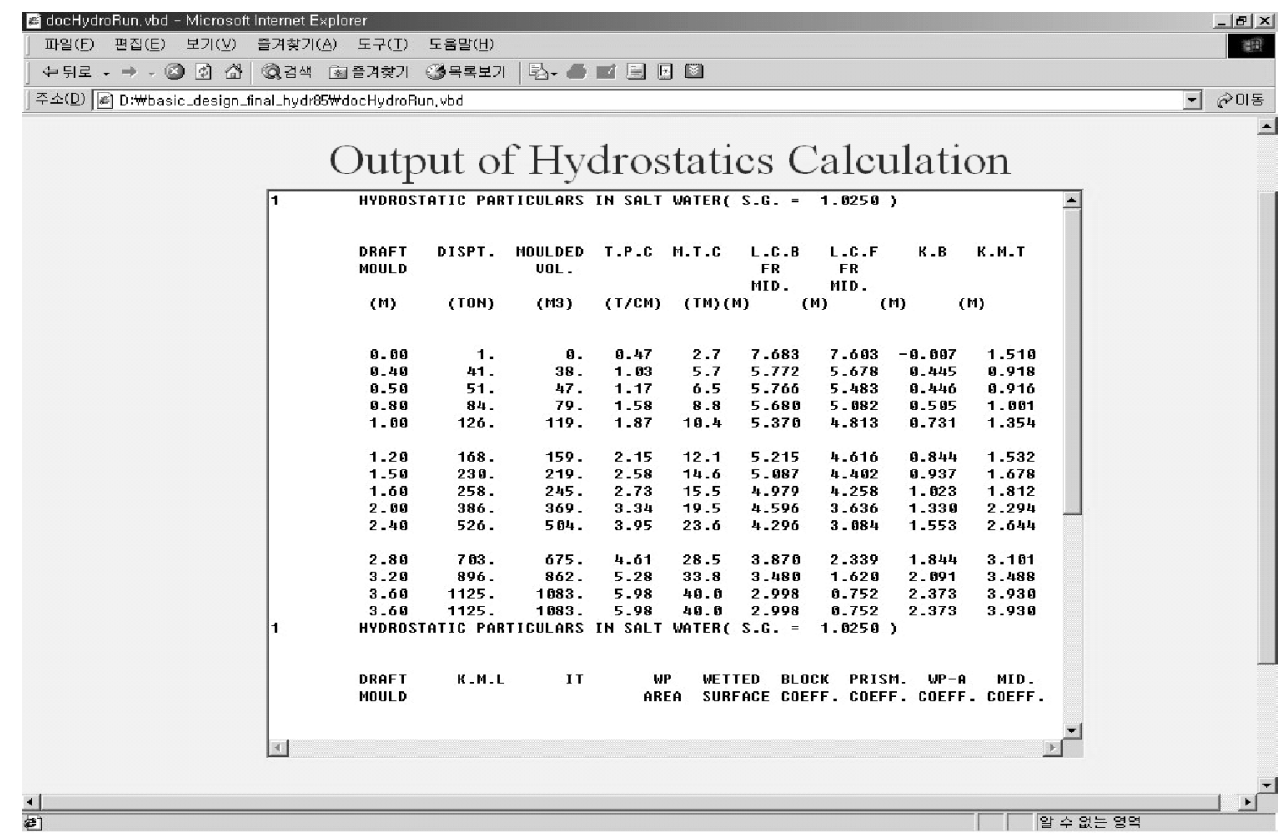

Fig. 10 Result screen of hydrostatic calculations.

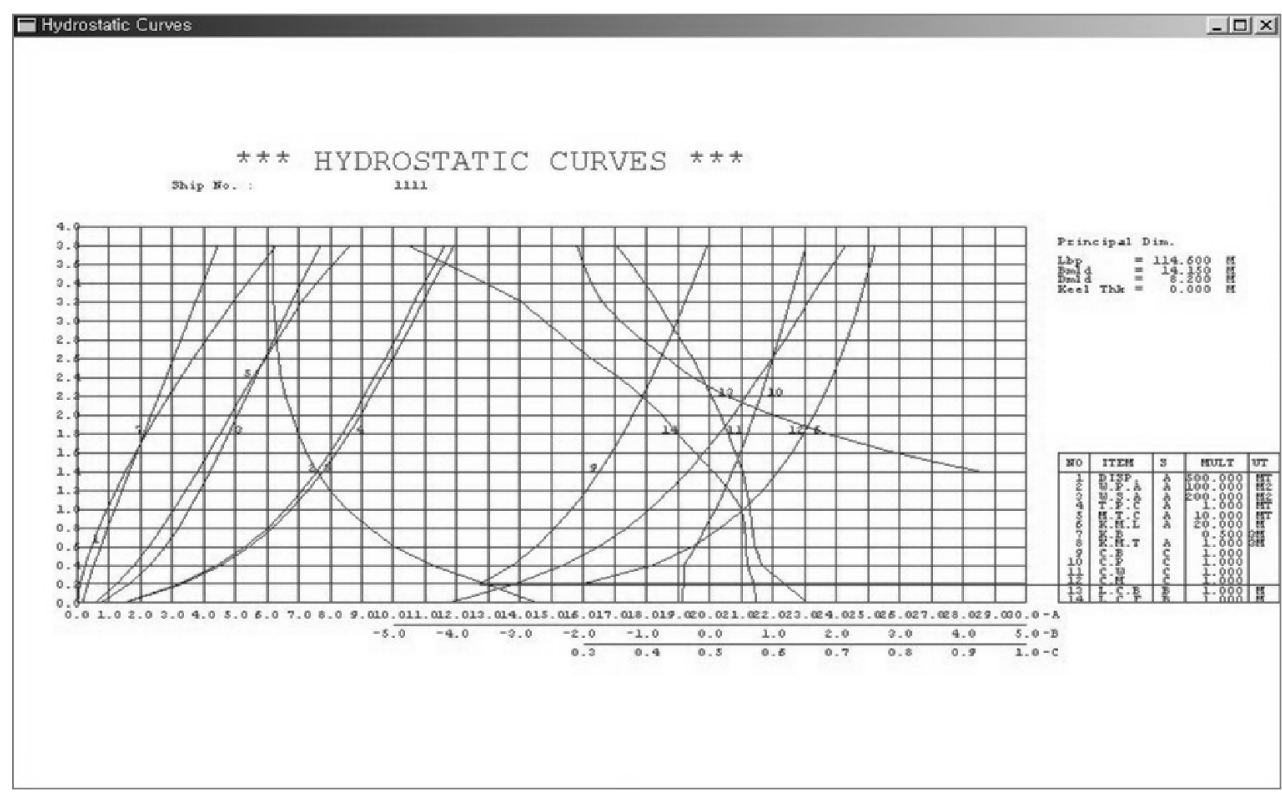

Fig. 11 Hydrostatics curve. 


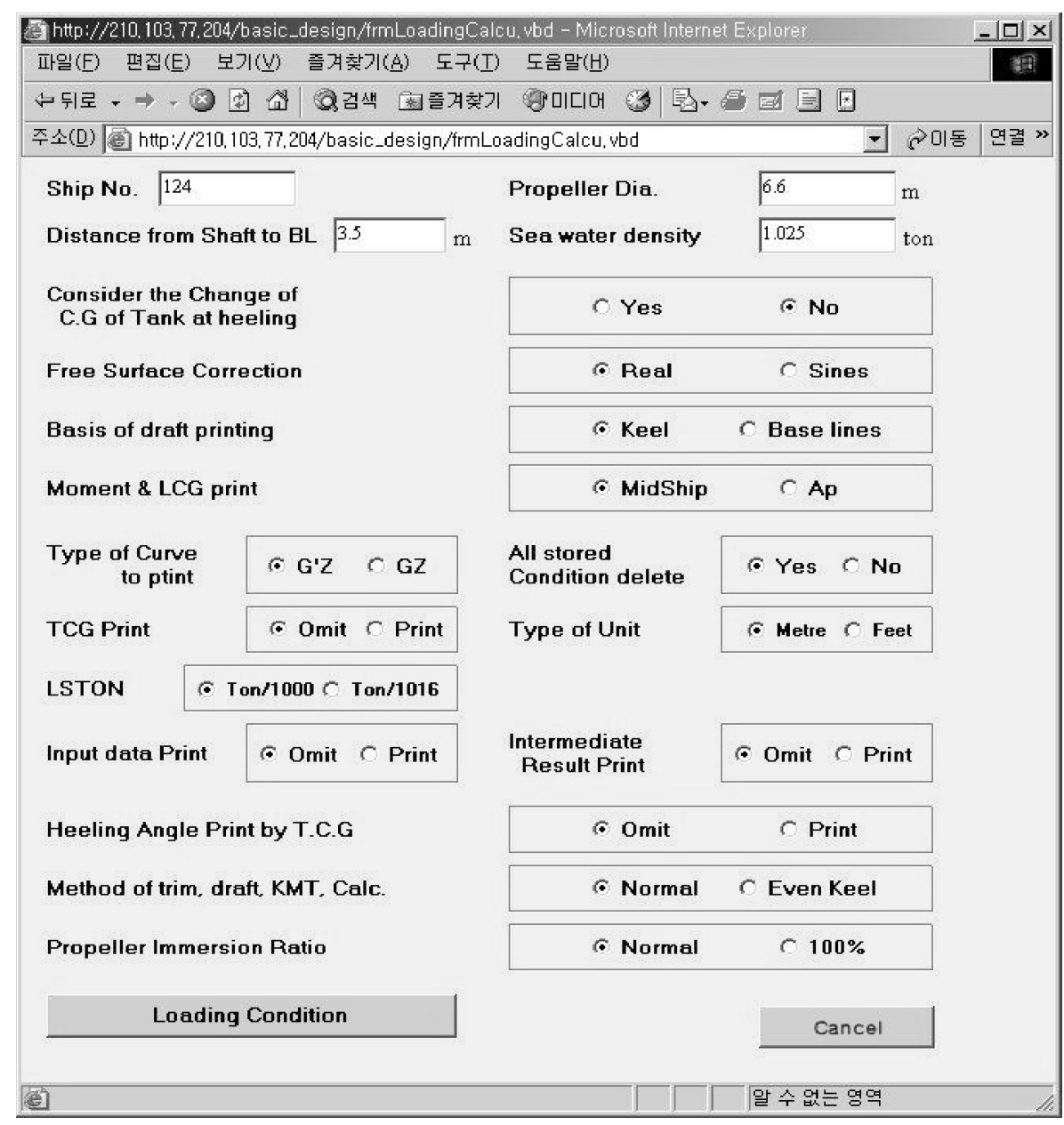

Fig. 12 Data input screen for longitudinal strength calculation.

\section{CONCLUSIONS AND FUTURE WORKS}

In this paper, a prototype of the internet based design support system for small and medium sized shipyards, where the technological level is relatively lower than other major shipyards, is developed. The functions of the prototype system are divided into user management module, basic planning support module, and basic calculations module. The basic planning support modules are designed specifically for the small and medium sized shipyards, but calculations module can be used in other major shipyards or related institutes. The standardized data format is used for the a seamless information exchange between shipyards and design agents, and the system which is designed for removing redundant activities and data loss may increase overall design efficiency. Especially in distributed environment, the use of internet environment enables remote design and easier design information exchange between shipyards and design agents.

When the remote design system for small and medium sized shipyards is established, the competitiveness of these shipyards will be increased, and core technology for remote ship design support center will also be acquired.

The practical significances of the research are as follows:

The developed system will help reduce design time and cost.

The information model of developed system is tightly integrated as an object-oriented infrastructure to provide the basic construct for integrated system development.

The approach and proposed methodologies can be employed to facilitate the development of other internet based tools and system.

In the future, the developed system will be continuously evaluated and it will be applied to the real design process in small and medium sized shipyards. Also, the system will implement the international standards including STEP AP215 (Ship arrangements) and AP216(Ship moulded form). 


\section{ACKNOWLEDGEMENTS}

The contents of this paper are the results of Ministry of Knowledge Economy research project, "The Development of Internet Based Basic Planning Support System”.

\section{REFERENCES}

Chun, B.S., 1997. ActiveX Programming Guide. Power Book, Korea.

Hwang, H.J., 2010. Development of conformance testing criteria for STEP AP218. Journal of Ocean Engineering and Technology, Korea, 24, pp.74-81.

Lee, T.S., 2000. about ASP 3.0. YoungJin.com.

Lee, S.S., Kim, Y.D., Seo, J.W. and Kim, S.Y., 2003. Development of Test case of STEP Ap216 for the Exchange of hullform data. Transaction of the Society of CAD/CAM Engineers, Korea, 8, pp.141-149.

Lee, S.S. and Lee, D.K., 2008. Development of integrated system for safety assessment of damaged ship. Transaction of the Society of CAD/CAM Engineers, Korea, 13, pp.227-234.

Lee, J.K., Lee, D.K., Lee, S.S., Kim, H.T., Kim, Y.D., Lee, K.H., Jang, S. and Kim, K.W., 2000. The Development of the Next Generation Ship Production System Technology (V) - The Next Generation Ship Production System (Shipbuilding CIM) Integration Technology, Korea, KRISO Research Report.

Lee, D.K., Lee, S.S. and Park, B.J., 2004. 3-D geometric modeler for rapid ship safety assessment. Ocean Engineering, 31, pp.1219-1230.

Lee, S.S., Lee, J.K., Park, B.J., Lee, D.K., Kim, S.Y. and Lee, K.H., 2006. Development of internet based ship technical information management system. Ocean Engineering, 33, pp.1814-1828.

Pedro, G., 1997. Telematics: A challenge to Concurrent Engineering, Proceedings of the 9th International Conference on Computer Applications in Shipbuilding, pp. 411-424.

Song, H.J., 1998. Visual Basic6. Hancom Press: Korea.

Schaffran, R.W. and Dallas, A., 1997. MARITECH Advanced information Technology Projects for U.S. Shipbuilding Industry, Proceeding of ICCAS'97, 1, pp.11-30. 